\title{
Aplicando a Responsabilidade Objetiva (Strict Liability) aos Serviços: Uma Perspectiva a Partir dos Estados Unidos
}

\section{William Powers Jr. ${ }^{*}$, Dean, John, Jeffers Researsh Chair, Hines H. Baker and Thelma Kelley Baker Chair in Law and University Distinguished Teaching Professor}

\section{Introdução}

Nos Estados Unidos, o termo responsabilidade civil pelo fato do produto (products liability) se refere a um tipo de caso, não se referindo a uma única teoria de reparação ou uma única causa de ação. Assim, a pessoa que é lesionada por um produto pode processar o vendedor baseado em uma teoria de responsabilidade contratual como a da quebra de um contrato, a quebra de uma garantia prevista pela Common Law ou pela quebra da garantia regulada pela Uniform Commercial Code - ou ainda por uma teoria de responsabilidade por ilícito civil - como culpa, fraude, ou responsabilidade objetiva (strict liability). De fato, o autor pode se basear em diversas teorias para fundamentar o mesmo caso.

Algumas dessas teorias de responsabilidade - quebra de contrato, quebra de garantia na Common Law, fraude e culpa - foram desenvolvidas fora da área da responsabilidade pelo fato do produto e são geralmente aplicáveis a casos que não envolvem produtos. Mas as duas teorias mais importantes - responsabilidade objetiva (strict liability) e quebra de garantia (breach of warranty) regulada pela Uniform Commercial Code - aplicam-se apenas para vendas de bens e produtos. Em razão da responsabilidade objetiva pelo fato do produto (strict products liability) seu padrão especial de responsabilidade seletivamente, os tribunais devem ser capazes de identificar casos que preencham este objetivo. Esta tarefa tem sido especialmente difícil em casos que envolvem a contratação de serviços. Embora a maioria dos tribunaus tenham decidido que serviços "puros" estão além do objetivo da teoria de responsabilidade objetiva pelo fato do produto (strict product liability), já que não se trata de venda de produtos, algumas transações são difíceis de se classificar por envolverem, simultaneamente, um produto e um serviço. Os tribunais têm confiado em vários fundamentos básicos para determinar se casos híbridos de venda de produto e prestação de serviço são resolvidos pela teoria da responsabilidade objetiva pelo fato do produto (strict product liability), mas têm falhado em desenvolver uma análise para distinguir produtos de serviços.

* Tradução de Rafael Pellegrini Ribeiro e Antonia Longani Klee (Grupo de Pesquisa CNPq Mercosul e Direito do Consumidor) e revisão de Thomaz de Araújo Santos (Grupo de Pesquisa CNPq Mercosul e Direito do Consumidor), e Marcelo Leal (PPGDir/UFRGS). 
Um grande impedimento para uma melhor análise dos casos híbridos de venda de serviços é que este problema consiste, na verdade, em quatro assuntos diferentes que os tribunais tendem a associar. A primeira questão, que é o principal foco deste estudo, é saber como serviços e produtos podem ser diferenciados. Por exemplo, se um encanador que instala de forma errada um aquecedor de água quente esta lidando com um produto (o aquecedor instalado) ou com um serviço (a instalação).

Uma segunda questão é saber se a transação que envolve um produto também envolve a sua venda. Este assunto é comum nos casos híbridos de venda de produtos e serviços, já que fornecedores de serviços freqüentemente usam produtos enquanto executam seus serviços. Por exemplo, uma tintura para cabelo é claramente um produto, mas não é tão claro se um salão de beleza que o aplicou em um cliente o vendeu ou simplesmente o usou enquanto executava um serviço. Da mesma forma, uma seringa descartável é um produto, mas se um médico a usa em um paciente ele estaria vendendo este produto ao paciente?

Uma terceira questão seria se réus que atuam como profissionais merecem tratamento especial. Muitos dos casos de venda de produtos e serviços acontecem em situações que envolvem serviços profissionais, especialmente serviços relacionados à saúde, e geralmente não fica claro se o entendimento dos tribunais se aplica igualmente para serviços de não-profissionais. Uma última questão é saber se a distinção de venda de produtos e serviços em casos baseados em responsabilidade objetiva fundamentada em ilícito civil (strict tort liability) é a mesma como a distinção entre venda de produtos e serviços nos casos baseados nas garantias previstas no artigo $2^{\underline{O}}$ do Uniform Commercial Code.

Cada uma dessas questões é importante por si só, mas o propósito principal deste estudo é examinar a primeira: a distinção entre produtos e serviços. Não obstante, as outras três questões sejam relevantes pelo fato das cortes entrelaçarem todas as quatro questões em casos envolvendo transações híbridas de vendas e serviços. Já que a maioria dos casos de venda de produtos e serviços envolvem mais de uma das quatro questões é normal encontrar dificuldades para determinar como cada uma delas se aplica a um caso particular, especialmente pela distinção pouco cuidadosa feita pelos tribunais.

Os tribunais devem, primeiramente, distinguir estes assuntos distintos antes que se faça algum progresso no sentido de um entendimento quanto a distinção entre a venda de produtos e serviços. Enquanto o foco está na distinção entre produtos e serviços na teoria da responsabilidade objetiva por ato ilícito (strict tort liability), é importante entender que uma posição aparente de um tribunal nessa questão pode ser influenciada pela falha deste tribunal em distingui-la de uma ou entre aquelas outras três questões.

Mesmo se os tribunais separassem a distinção entre produto e serviço desses outros assuntos, a distinção em si apresenta problemas que têm um duplo significado. Além de impedir a resolução de casos específicos, a falha em desenvolver uma abordagem 
compreensiva para a distinção entre produto e serviço revela um problema latente da responsabilidade objetiva pelo produto (strict product liability). Uma premissa da teoria da responsabilidade objetiva pelo produto (strict product liability) é que um produto que lesa constitui um problema à parte, que merece um tratamento especial. Por outro lado, seria inapropriado distinguir lesões causadas pelos produtos de outras lesões pessoais, em que a responsabilização é fundada na culpa. Mas os tribunais nem sempre articularam claramente as características de um caso de produto e as políticas que eles invocam e que diferenciam lesões causadas por produtos de outras lesões pessoais. Sem um claro entendimento de porquê os casos de produtos são diferentes, tem sido difícil precisar o que se constitui um caso de produto em situações-limite, apresentadas por transações híbridas de produtoserviço.

Ambos os proponentes e oponentes da responsabilidade objetiva pelo fato do produto (strict product liability) têm se fundamentado em vários argumentos para apoiar as suas respectivas posições. No entanto, muitos dos argumentos de ambos os lados não fazem distinção entre os danos causados pelo produto de outros danos pessoais; eles o aplicam igualmente a todos os casos de danos pessoais. Conseqüentemente, tais argumentos não explicam o uso da teoria da responsabilidade objetiva (strict liability) em casos de produtos e não ajudam na identificação de casos de produto em situaçõeslimite. A dificuldade que as cortes têm encontrado em tentar definir os limites da responsabilidade objetiva por produtos (strict products liability) nos casos híbridos de produto-serviço reflete a confusão a respeito dos valores que tal regime de responsabilidade se destina a abarcar.

Este trabalho examina a distinção entre produtos e serviços da perspectiva de desenvolvimento de um padrão coerente e funcional de distinção entre produtos e serviços em casos específicos, e da perspectiva de adquirir conhecimento da estrutura mais ampla da responsabilidade objetiva pelo produto (strict product liability). A segunda parte do estudo tenta desenvolver uma abordagem compreensiva que pode ser usada pelos tribunais para analisar os casos de responsabilidade objetiva pelo fato de produtos (strict products liability) ou de serviços. Conclui que os tribunais devem adotar uma abordagem que atente às razões para a distinção entre danos causados por produtos e outros danos pessoais causados por culpa em primeiro lugar. A terceira parte explora algumas das implicações que os casos híbridos de venda de produtos e serviços têm na responsabilidade objetiva pelo produto (strict product liability).

\section{Para uma abordagem geral da distinção entre produtos e serviços}

Uma abordagem geral da distinção entre produtos e serviços requer respostas a duas perguntas distintas, porém relacionadas: (1) se se deve incluir os serviços puros na teoria da responsabilidade objetiva pelo produto (strict product liability); e (2) se a transação de serviços puros for excluída, como se distinguir entre produtos e serviços 
nos casos híbridos de transações de produtos e serviços. Embora essas perguntas sejam distintas elas estão relacionadas: a distinção entre produtos e serviços em casos híbridos deveria ser feita de maneira consistente com as razões para o tratamento diferenciado dado a produtos e serviços, em primeiro lugar.

\section{A. A distinção básica entre produtos e serviços}

Enquanto alguns doutrinadores sustentam que a responsabilidade objetiva (strict liability) deveria ser aplicacada aos serviços comerciais, quase todos os tribunais têm recusado estender tal teoria a simples transações de serviços puros. Não se chegou a um consenso semelhante a respeito da razão para a exclusão dos serviços da responsabilidade objetiva por produto (strict procucts liability).

\section{História "legislativa"}

Um dos argumentos é de que os "autores" da seção 402A não pretendiam incluir transações de serviços puras em seu escopo. Embora a linguagem da seção $402 \mathrm{~A}$ leve a entender que houve a exclusão dos serviços, o tribunal não deve interpreta-la como se fosse uma lei. Enquanto os tribunais são compreensivelmente influenciados pela seção $402 \mathrm{~A}$ em casos difíceis, o desenvolvimento dos princípios do Common Law é freqüentemente obstaculizado quando os tribunais abdicam cegamente de sua linguagem. Ainda mais, se a linguagem da referida seção proporcione um argumento persuasivo para a exclusão dos serviços da responsabilidade objetiva (strict liability), ela não avança na análise nos casos híbridos de venda da produtos e serviços, já que não explica por que os produtos recebem tratamento diferente dos serviços.

\section{Alegações de imperfeições não têm sentido para os serviços}

Um segundo argumento é que o conceito de imperfeição ou de uma garantia implícita faz pouco sentido quando aplicado a serviços. O ponto principal da imperfeição é que, diferentemente da culpa, existe a tendência de se analisar mais o produto do que a atitude do produtor. Uma vez que um serviço envolve necessariamente mais uma conduta que um produto, um tribunal deveria ser chamado para avaliar a conduta do agente se a responsabilidade objetiva (strict liability) fosse aplicada a serviços.

Esse argumento não é convincente. As cortes podem distinguir entre imperfeição e culpa, mesmo em serviços, analisando mais os resultados do serviço do que a conduta do prestador, o que seria apropriado no caso de culpa. Analisando desta forma, um médico que diagnosticasse erroneamente uma doença teria prestado um serviço imperfeito, da perspectiva de nosso conhecimento, no momento do julgamento, mesmo se o diagnóstico fosse razoável da perspectiva do que o médico podia ter sabido quando o diagnóstico foi feito. O problema prático da confusão entre culpa e imperfeição pode ficar exacerbado em serviços, já que a conduta do prestador deverá ser examinada, mas não há nenhuma barreira conceitual para a aplicação da responsabilidade objetiva a serviços. 


\section{Uma abordagem pontual}

Uma terceira razão para a exclusão dos serviços da teoria da responsabilidade objetiva (strict liability) se centra em alguns aspectos específicos das transações envolvendo serviços. Por exemplo, no caso Gagne v. Bertran ${ }^{1}$, a Suprema Corte da Califórnia se recusou aplicar a responsabilidade objetiva (strict liability) para um Engenheiro de Solos porque os consumidores não esperam que este serviço esteja livre de defeitos:

"(O engenheiro) estava vendendo um serviço, e não um seguro. Assim, a regra geral que se aplica é que aqueles que vendem seus serviços para a orientação de outros em suas relações econômicas, financeiras e pessoais não são responsáveis na ausência de culpa ou por serviço intencionalmente mal prestado".

(...).

"Os serviços de especialistas são necessários pelas suas habilidades. Eles têm o dever de exercer a habilidade e a competência dos membros de sua profissão, e uma falha no exercício de tal habilidade irá acarretar responsabilidade por culpa. Aqueles que contratam estes especialistas não têm justificativa em esperar infalibilidade, mas devem esperar competência e cuidado no exercício de tal habilidade especial. Estes compram um serviço e não um seguro".

O problema deste argumento é que o mesmo poderia ser dito daqueles que selecionam produtores. Argumentos para defender a culpa ou a responsabilidade objetiva (strict liability) podem ser usados para qualquer tipo de acidente. A questão, no entanto, está em determinar o tratamento especial dos serviços em um sistema que distingue entre os danos causados por produtos de outras lesões pessoais. $O$ argumento no caso Gagne não distingue prestação de serviço da venda de um produto e, portanto, não justiça um tratamento distinto.

Esta abordagem pontual que foca somente a natureza da prestação de serviço tem sido usada em outros casos com mais sofisticação. Um doutrinador desenvolveu um modelo complicado baseado na informação e na teoria do marketing e concluiu que a responsabilidade objetiva (strict liability) seria aplicável em alguns casos de prestação de serviços. A analise distingue diferentes tipos de prestação de serviço e oferece razões de porque a responsabilidade civil objetiva (strict liability) deveria ser aplicada em cada um deles, mas ela nem tenta demonstrar sua aplicação em outros casos como acidentes automotivos no qual a responsabilidade civil objetiva (strict liability) é claramente não aplicável. Conseqüentemente, o argumento não justifica o uso seletivo da responsabilidade objetiva (strict liability) em prestação de serviços quando a culpa é necessária em outros casos de lesão pessoal.

\footnotetext{
1 - 43 Cal. 2d 481, 275 P.2d 15 (1954).

2 - Id. At 487-89, 275 P.2d at 20-21.
} 


\section{Analogias de uma via}

Um quarto tipo de argumento vai além do tópico das prestações de serviço isoladas e as compara com outros tipos de casos, cuja resolução é sabida ou presumida. Por exemplo, os partidários da responsabilidade objetiva (strict liability) argumentam que as políticas de aplicação da responsabilidade objetiva em produtos (strict products liability) (como a da distribuição do risco) também são aplicáveis aos serviços. Reciprocamente, um oponente à aplicação da teoria da responsabilidade objetiva (strict liability) aos serviços argumenta que as políticas que apóiam a rejeição da aplicação da responsabilidade objetiva (strict liability) aos serviços médicos são também aplicadas aos serviços que não são relacionados com a medicina.

Essas "analogias de uma via" são de grande ajuda, mas não dão atenção à possibilidade de que serviços podem ser também análogos a outros casos em que o tratamento legal é diferenciado. Por exemplo, serviços podem ser análogos a produtos porque, em cada situação, os custos com acidentes podem ser internalizados nos preços e repassados aos consumidores. Mas os custos com acidentes de uma atividade também podem ser internalizados no preço da atividade ao sujeitá-la à responsabilidade objetiva (strict liability). Esta característica dos serviços faz com que sejam análogos tanto a produtos quanto a outros causadores de acidentes que são normalmente dirigidos pela culpa, e, conseqüentemente, não se escolhe entre um tratamento divergente dado a um dano causado por produto e outros acidentes.

Outros acidentes, como acidentes de automóvel, e danọs com produtos possuem algumas características, porém são tratados de forma diferenciada. Os tribunais devem descobrir o que distingue os casos de acidentes com produtos de outros tipos de acidentes (e por que) e então devem determinar se os casos de serviço são mais semelhantes a um ou outro, tendo em vista os motivos para diferenciá-los. A "analogia de uma via" não consegue demonstrar isso.

\section{Analogias de duas vias}

Alguns tribunais têm ido além das "analogias de uma via" e têm se valido de políticas que distinguem danos por produtos de outros danos pessoais e assim justificam a responsabilidade objetiva em casos envolvendo produtos (strict procucts liability). Por exemplo, no caso Lemley v. J\&B Tire Co. ${ }^{3}$, o tribunal decidiu que casos com produtos são diferenciados, já que dificulta a prova para a vítima. A conduta do produtor normalmente ocorre em tempo e espaço remotos em relação ao acidente ficando difícil para o autor identificar fatos específicos a respeito da conduta do produtor. Os problemas com a prova geralmente não são tão freqüentes em casos que não envolvem produtos, já que a alegada conduta culposa do demandado pode ser identificada de forma mais acessível. O tribunal do caso Lemley, então, concluiu que esta característica de distinção dos casos envolvendo produtos não era uma característica marcante das prestações de

3 - 426 F. Supp. 1378,1380 (W.D. Pa. 1977) 
serviço e conseqüentemente recusou a aplicação da responsabilidade objetiva (strict liability) a um caso envolvendo um mecânico.

Não obstante os resultados específicos do caso Lemley, a abordagem básica do tribunal é clara. Ao invés de fazer referências gerais aos argumentos favorecendo ou desfavorecendo a responsabilidade objetiva (strict liability) o tribunal focou políticas específicas para distinguir lesões causadas por produtos das lesões pessoais e que, portanto, justificam o uso seletivo da responsabilidade civil objetiva (strict liability) em casos que envolvam produtos.

A chave para esta abordagem está em identificar políticas que distinguam lesões causadas por produtos de outras lesões pessoais. Muitas das políticas avançadas para embasar a responsabilidade pelo fato dos produtos (products liability) são convincentes dentro do contexto de um caso específico, mas não são igualmente aplicáveis em casos que não envolvam produtos. Conseqüentemente eles não explicam o tratamento distinto recebido pelos caos que envolvam produtos.

\section{(a) Incentivos para a promoção de segurança}

Um argumento comum para a aplicação da responsabilidade objetiva para os produtos (strict procucts liability) é a promoção da segurança na produção destes produtos, pois requerer dos produtores que eles arquem com os custos dos acidentes independentemente de culpa lhes concedendo um incentivo a produzir produtos mais seguros. É passível de debate tanto analítica como empiricamente se a responsabilidade objetiva (strict liability) aumenta a segurança do produto, tanto quanto o optimizaria. Mais importante para o presente questionamento, no entanto, é a falha deste argumento em distinguir entre danos causados por produtos e outras lesões pessoais. A responsabilidade objetiva (strict liability) em casos de acidentes de trânsito também internalizaria o custo dos acidentes no custo de dirigir, trazendo, portanto, um incentivo de segurança. Os incentivos de segurança podem embasar a responsabilidade objetiva (strict liability) em geral (dependendo da evidência empírica), mas não esclarecem a aplicação seletiva da responsabilidade civil objetiva (strict liability) nos danos causados por produtos.

(b) Distribuição do risco

Um segundo argumento para a aplicação da teoria da responsabilidade objetiva aos produtos (strict procucts liability) é que ajudam na internalização de custos com acidentes nos preços dos produtos. Mesmo se a distribuição de riscos for uma meta desejável, o que é em si mesmo controverso, ela não é específica para lesões derivadas de produtos. Vítimas de outros acidentes poderiam também ter suas perdas distribuídas. No caso de acidentes automobilísticos (uma grande parte dos casos é decorrente tão somente de culpa), os custos dos acidentes poderiam ser distribuídos entre motoristas através de um mecanismo de seguro automotivo universal, ou próximo disso. De fato, vítimas de doenças e desastres naturais são indistinguíveis de vítimas de produtos da 
perspectiva da distribuição de perdas. Acrescente-se, no presente contexto, que o argumento para a distribuição de riscos é igualmente forte para lesões causadas por produtos não defeituosos, ainda assim a reparação é uniformemente negada em tais casos. Embora a retórica da distribuição de riscos seja freqüentemente usada para fundamentar a responsabilidade civil objetiva pelo fato do produto (strict products liability) para vítimas de produtos defeituosos, não se justifica o seu uso seletivo.

(c) Dificuldade em provar atos específicos de culpa

Um terceiro argumento para a responsabilidade objetiva por produtos (strict procucts liability) é que ela é indevidamente onerosa para um autor provar atos específicos de culpa em um caso de produtos. Provar culpa é difícil em qualquer caso de dano pessoal. Testemunhas podem dar versões conflitantes dos eventos, e o mecanismo causador do dano pode ter sido destruído no acidente. Entretanto, o problema é mais grave em casos de produtos, uma vez que a culpa alegada normalmente ocorre num local controlado pelo réu, antes de o autor ter adquirido o produto. Mesmo que isso algumas vezes aconteça em casos que não envolvem produtos, por exemplo, quando um motorista falhou em manter seus freios de maneira adequada, danos causados por produtos apresentam esse problema mais gravemente do que outros danos. Conseqüentemente, os tribunais podem, consistentemente amparar os autores do ônus de provar culpa em casos envolvendo produtos, enquanto requerem prova de culpa em outros casos de danos pessoais.

Esta razão para responsabilidade objetiva de produtos (strict procucts liability) não nega a culpa como a motivação subliminar para responsabilidade. Ela propõe que a culpa seja uma causa comum para produtos defeituosos e que uma inabilidade do autor em provar culpa é preferencialmente uma conseqüência da dificuldade de provar do que o fato de o fabricante ter realmente sido culpado.

Esta razão é especificamente atrativa porque se harmoniza com medidas específicas de responsabilidade objetiva de produtos (strict procucts liability), de uma forma que outras razões não se harmonizam. Por exemplo, a explicação do "perigo inevitável" de excluir da responsabilidade objetiva (strict liability) a infecção do plasma sangüíneo por hepatite 4 e a "defesa do trabalho perfeito" (state of the art defense) são essencialmente fixadas em conclusões de que não se poderia esperar que o fabricante tivesse feito o produto mais seguro. A distribuição de risco não explica essas defesas, uma vez que estes riscos são tão passíveis de distribuição quanto quaisquer outros. Contudo, não obstante a normal conclusão de culpa pelo defeito, estamos habitualmente convencidos de que um fabricante não foi negligente nos casos que envolvem perigo inevitável ou tecnologia de ponta. A falha do autor em provar culpa, nesses casos, não deve ser atribuída meramente ao problema de provas.

${ }^{4}$ Veja, por exemplo, Brody v. Hospital Overlook, 127 N.J. Super. 331, 339-40, 317 A.2d 392, 297 (1974), affd per curiam, 66 N.J. 4489, 332 A.2d 596 (1975). Mas veja Cunningham v. MacNeal Memorial Hospital, 47 III. 2d 443, 453-56, 266 N.E.2d 897, 902-03 (1970). 
Diferente de outros argumentos, a questão da prova é também consistente com a negação dos tribunais em compensar as vítimas de produtos que não são defeituosos. Por um lado, um defeito levanta uma presunção de culpa muito mais forte do que uma mera lesão (ou dano, ou injúria). Por outro lado, enquanto o defeito não é facilmente comprovável, um autor tem, pelo menos, acesso contemporâneo ao produto, atenuando os problemas especiais de provar culpa em um caso envolvendo produtos.

A importância da questão da prova em casos de responsabilidade objetiva de produtos (strict procucts liability) é que, enquanto não necessariamente representa uma boa política, ela distingue danos causados por produtos de outros danos pessoais e por isso promove uma base plausível para seletivamente evitar culpa em casos de produtos. Conseqüentemente, sua aplicação aos casos de serviços pode ser utilizada para assegurar se elas falharem com o objetivo de responsabilidade objetiva (strict liability).

\section{(d) Expectativas do Consumidor}

Um quarto argumento reflete a garantia herdada da responsabilidade objetiva de produtos: produtos defeituosos frustram as expectativas dos consumidores. Especialmente nos casos mais antigos, os tribunais confiaram em garantias gerais de segurança e qualidade que eram encontradas em anúncios ou na mera propaganda de um produto. Foi dado ênfase nas expectativas dos consumidores tanto para um teste de defeitos, quanto por motivos de responsabilidade. Os tribunais têm desejado livrar a responsabilidade de produtos de suas amarras garantistas, e expectativas concretas dos consumidores são dificilmente determinadas nesses casos, a não ser as mais simples. Do ponto de vista de que as expectativas dos consumidores permanecem a base para a responsabilidade objetiva de produtos (strict procucts liability), entretanto, esta razão justifica a distinção entre casos envolvendo produtos (nos quais a barganha pode criar expectativas) e outros casos causadores de danos pessoais (nos quais não são criadas expectativas).

(e) Os fabricantes estão em uma posição melhor para prevenirem danos

Um quinto argumento para responsabilidade objetiva de produtos (strict procucts liability) coloca o peso dos danos nos fabricantes, que estão em posição melhor para prevenir o dano, "do que nas pessoas lesadas que não têm força para se protegerem ${ }^{5 "}$. Esta razão é por si controvertida, mas o que é mais importante é o fato de ela não distinguir danos causados por produtos de outros tipos de danos pessoais. Vítimas de acidentes automotivos estão comumente "sem força" para se protegerem, e um suposto autor de um delito civil está em posição melhor para prevenir a perda. De fato, em transações envolvendo consumidores, a vítima tem pelo menos a oportunidade de selecionar o fabricante, uma escolha que habitualmente não lhe é dada em caso de acidente automotivo.

${ }^{5}$ Greenman v. Yuba Power Prods., Inc. 59 Cal. 2c 57, 63, 377 P.2d 897, 90127 Cal. Rptr. 697, 701 (1963). 
(f) Fabricantes impõem riscos deliberadamente

Um argumento final de responsabilidade objetiva de produtos (strict procucts liability) - calcada na justiça - requer que o fabricante compense as vítimas por deliberadamente impor riscos aos consumidores para seu benefício próprio. Argumentos similares foram usados para explicar a teoria geral de responsabilidade por ilícito civil, e nisto reside sua fraqueza como uma justificação para o tratamento especial dos danos causados por produtos. Motoristas deliberadamente impõem riscos aos pedestres para seu próprio benefício, já a prova de culpa mesmo assim é requerida.

(g) Aplicação das razões à distinção entre produto e serviço

Desses argumentos, apenas dois explicam a distinção entre danos causados por produto e outros danos pessoais: (1) os problemas singulares de prova que um autor confronta em um caso envolvendo produtos; (2) a representação tácita de segurança que constitui parte da barganha do consumidor. As outras razões putativas para responsabilidade objetiva de produtos (strict procucts liability) sustentam geralmente a responsabilidade objetiva (strict liability) por ilícito civil, não sua aplicação seletiva nos casos envolvendo produtos defeituosos.

Os dois argumentos que distinguem entre danos causados por produtos e outros danos pessoais sugerem a oposição de resoluções de casos envolvendo serviços puros. $\mathrm{O}$ argumento baseado em representações implícitas de qualidade e segurança parece ser igualmente poderoso em casos envolvendo serviços, desde que ambas sejam "contratuais" e, conseqüentemente, elevem as expectativas dos consumidores. A questão da prova, entretanto, distingue entre serviços e produtos, porque os obstáculos especiais de prova encontrados por autores em casos de produtos não são tão graves quanto em casos envolvendo serviços. $\mathrm{O}$ alegado desacerto em transações de serviços geralmente ocorre em um local acessível ao consumidor, depois de o consumidor ter escolhido o fornecedor de serviços.

Dependendo da escolha feita pelo tribunal, entre essas razões, um sistema coerente de responsabilidade poderia tanto incluir como excluir casos de serviços da esfera de ação da responsabilidade objetiva (strict liability). Embora o problema da prova explique melhor o tratamento especial dado a casos envolvendo produtos, um tribunal poderia plausivelmente confiar em qualquer um dos argumentos apresentados e tratar casos envolvendo serviços tanto como casos envolvendo produtos ou como casos envolvendo acidentes entre estranhos.

Depois que um tribunal faz essa determinação, entretanto, sua gama de aproximações em casos híbridos é mais limitada. Se o tribunal decide tratar serviços como produtos, os casos híbridos deixam de ser problemáticos: eles também seriam governados pela responsabilidade objetiva (strict liability). Se um tribunal decide excluir serviços puros da responsabilidade objetiva (strict liability), entretanto, ele deve, então, decidir como tratar um caso híbrido, se como um produto, ou como um serviço. Isto se dá porque a maioria dos tribunais declinou de estender a responsabilidade objetiva a serviços puros, que os casos híbridos continuam a nos deixar perplexos. 
Neste ponto, entretanto, a análise pode ser simplificada, porque apenas a questão probatória distingue casos envolvendo produtos dos acidentes automotivos e dos casos puros de serviços. Embora um tribunal possa vindicar a argumentação da representação estendendo a responsabilidade objetiva a serviços puros, apenas a questão probatória fornece uma explicação satisfatória para o direito corrente em jurisdições que requeiram a prova do defeito em casos envolvendo produtos e excluem serviços puros do alcance da responsabilidade objetiva (strict liability). Com efeito, os tribunais deveriam confiar nesse argumento para determinar se casos híbridos específicos são mais parecidos com produtos (e governados pela responsabilidade objetiva (strict liability)) ou se são mais parecidos com serviços (e governados pela culpa).

\section{B. A Distinção entre Produto e Serviço em Casos Híbridos}

Se os casos envolvendo produtos são especiais por causa de seus graves problemas de prova, poderia ser possível resolver casos híbridos de produtos e serviços de acordo com essa distinção. Os tribunais deveriam averiguar se um caso híbrido é o tipo de caso que evoca a questão da prova da responsabilidade objetiva de produtos (strict procucts liability).

Esta tarefa poderia ser complementada em vários níveis de generalidade ou especificidade. Em um extremo, um tribunal poderia examinar uma transação inteira - através da perspectiva de provar atos específicos de culpa - e determinar se é, como um todo, mais parecido com um serviço ou um produto. Um teste correntemente utilizado por alguns tribunais - o teste da essência da transação (the essence of the transaction test) - adota este tipo de abordagem, embora os tribunais não tenham visto explicitamente a transação pela perspectiva da questão probatória. Um tribunal seguindo essa abordagem não diferenciaria entre porções separadas de uma transação ao determinar se o caso envolveu um produto ou um serviço. Por exemplo, um bombeiro que instala um aquecedor de água seria julgado por um único teste, sem considerar em que momento a instalação do aquecedor de água foi defeituosa.

Um tribunal, entretanto, pode analisar as transações mais detalhadamente, para verificar a aplicabilidade da questão probatória nas suas porções específicas. Para o bombeiro que instala o aquecedor de água, a instalação defeituosa pode ser considerada um serviço, desde que tenha ocorrido em um local acessível para o consumidor, depois de ele ter selecionado o bombeiro. Um defeito no aquecedor de água, entretanto, iria sujeitar o consumidor a obstáculos de prova que fazem os danos causados por produtos serem especiais, e pode por isso ser governado pela responsabilidade objetiva (strict liability). Pelo o aquecedor de água em si, o bombeiro seria tratado como um vendedor de um produto defeituoso.

A Verificação de uma transação híbrida para determinar o tipo de defeito foi sugerido por alguns tribunais e doutrinadores. Por exemplo, no caso Barbee v. Rogers ${ }^{6}$ ${ }_{6}^{6} 425$ S.W.2d 342 (Tex. 1968). Veja também Nastasi v. Hochman, 58 A.D.2d 564, 396 N.Y.S.2d 216 (1977); Hoover v. Montgomery Ward \& Co., 270 Or. 498, 528 P.2d 76 (1974); Nota, supra nota 12 , em 402-04. 
a Suprema Corte do Texas recusou a aplicação da responsabilidade objetiva (strict liability) a um optometrista que teria impropriamente colocado lentes de contato em um paciente. Mesmo que a prática de uma profissão regularizada pelo réu fortemente influenciou o tribunal, também confiou no fato de que "a falta (dele)... reside nos atos profissionais dos (optometristas) e não na mercadoria que prescrevem, apropriadas e vendidas ". Mesmo que o tribunal não tenha baseado esta distinção na questão probatória quanto a responsabilidade objetiva de produtos (strict procucts liability), a natureza do defeito a atos específicos de culpa que ocorreram num tempo e num local remotos. Se as lentes tivessem sido feitas de material impuro, a rationale da prova teria sido comprometida e o optometrista poderia, razoavelmente, ser considerado confiável como um vendedor.

Os tribunais poderiam afinar bem suas análises mesmo além, perguntando-se, em cada situação de fato específica se a dificuldade de provar atos específicos de culpa foi excessivamente onerosa. Talvez haja casos tradicionais envolvendo produtos em que os problemas de prova não são graves, como um avião que foi fabricado sob o exame de inspetores independentes de segurança. Também pode haver, talvez, casos envolvendo puramente serviços em que os problemas com as provas são sérios, assim como um instrumento que foi enviado de volta ao fabricante para um reparo na "linha de montagem". Este nível adicional de boa afinação, no entanto, pode criar mais imprevisão do que sua flexibilidade adicional tem valor.

O ponto importante é que mesmo que a razão da prova distinga serviços de produtos, ela pode ser aplicada em vários níveis de generalidade ou especificidade. Examinando-se uma transação mais especificamente do que é contemplada pela essência da aproximação da transação provavelmente valha o problema; a diferença entre instalar um produto defeituoso e defeituosamente instalar um produto bom não é especialmente difícil para os tribunais assegurarem ou para os litigantes predizerem.

Há um outro tipo de caso híbrido que não é tão fácil de analisar de acordo como o tipo de defeito alegado. Transações tais como a instalação de um aquecedor de água, a prescrição de lentes de contato, ou a aplicação de um permanente nos cabelos são combinações de partes constituintes que podem ser classificadas elas mesmas facilmente como produto ou serviço, mas outras transações não são. Por exemplo, transmitir eletricidade e fornecer água contaminada parecem ser transações homogêneas, mas elas ainda são difíceis de serem catalogadas como produto ou serviço. Até mesmo aqui, um tribunal pode distinguir entre causas de um dano que são locais e contemporâneas (tal como a falha em retificar uma linha de transmissão de sotavento), e aquelas que são remotas e antigas (tais como estudos de engenharia sobre a localização de uma nascente d'água). Mas mesmo que alguns casos não são facilmente resolvidos, a razão da prova pelo menos fornece aos tribunais um método coerente e de analisar casos que estão na fronteira entre produtos e serviços.

Esta análise não soluciona outros problemas apresentados pelos casos híbridos de "venda-serviço": se profissionais garantem tratamento especial, se o teste em casos de

${ }^{7}$ Barbee 425 S.W.2d em 346. 
ilícitos civis deveriam ser similares ao teste de casos de garantias, e se um produto foi vendido ao contrário de ter sido meramente usado. Mas por um problema apresentado por casos híbridos de "vendas-serviço" - se um produto ou um serviço está envolvido - esta análise apresenta uma aproximação compreensiva que reflete uma teoria coerente para responsabilidade objetiva de produtos (strict procucts liability) em geral.

\section{Implicações da Distinção entre Produto e Serviço para Responsabilidade pelo Produto}

Os casos híbridos de venda de produtos e serviços são significativos além de suas resoluções imediatas. Alguns tribunais cuidadosamente analisam as razões para distinguirem entre danos causados por produtos e outros danos pessoais. Mesmo que os tribunais confiaram em numerosos argumentos para assegurarem a responsabilidade objetiva pelo produto (strict product liability), alguns tribunais justificaram a aplicação seletiva da responsabilidade objetiva (strict liability) a casos envolvendo produtos. Apenas os problemas graves de prova em casos de produtos podem justificar o direito atual que ambos excluem serviços puros da responsabilidade objetiva (strict liability) e nega o restabelecimento por danos causados por produtos que não são defeituosos.

Esta razão tem importantes aplicações para a responsabilidade objetiva pelo produto (strict product liability), porque ela intrinsecamente não rejeita a culpa como uma base para a responsabilidade. Melhor, ela usa o defeito como um artificialismo para a por razões "administrativas". Dispensando a exigência de que autores provem a culpa reflete uma decisão de que a decisão de que a culpa é muito difícil de ser determinada do que uma decisão de que réus inocentes deveriam ser confiáveis. De acordo com este ponto de vista, responsabilidade objetiva pelo produto (strict product liability) é uma forma de culpa per se, o que um tribunal reconheceu explicitamente.

Esta razão para a responsabilidade objetiva por produtos (strict procucts liability) ajuda a explicar as doutrinas específicas - tais como o estado de defesa da $\operatorname{arte}^{8}$ e a defesa de perigos inevitáveis - que desculpam fabricantes quando um pouco confiantes de que eles não foram, de fato, negligentes. Além disso, esta razão iria atenuar drasticamente os problemas que os tribunais têm encontrado ao coordenarem responsabilidade objetiva (strict liability) e culpa em casos envolvendo falta (ou culpa, ou erro, ou culpa, ou má-fé, ou ato ilícito) comparativa, tanto entre um réu objetivamente responsável e um autor negligente, ou entre réus procurando contribuição, alguns dos quais são negligentes e outros são objetivamente responsáveis. Desde que responsabilidade objetiva (strict liability) e culpa não são teorias antitéticas, sob essa razão para responsabilidade objetiva de produtos (strict procucts liability), elas poderiam ser unificadas mais facilmente.

Eu argumentei em outra ocasião que um reconhecimento explícito de falta (ou culpa, ou erro, ou culpa, ou má-fé, ou ato ilícito) como a base para responsabilidade

${ }^{8}$ Veja nota 5 supra. 
em casos envolvendo produtos não seria draconiana e desde logo iria atenuar numerosos problemas correntes que os tribunais estão enfrentando em responsabilidade pelos produtos. Sem repetir aquele argumento aqui, vale a pena notar que a presente análise das razões para responsabilidade objetiva por produtos (strict procucts liability) sugere que casos envolvendo produtos não são tão diferentes dos casos governados somente por culpa. Este não é um surpreendente subproduto da análise casos híbridos de venda de produtos e serviços, desde que eles formam uma porção significante da fronteira entre responsabilidade objetiva de produtos (strict procucts liability) e culpa. Enquanto a maioria dos problemas limítrofes envolve alguma ambigüidade, uma divisão coerente entre grupos de casos pelo menos deveria ter uma fronteira que respondesse a políticas que distinguem os dois grupos. Se uma barreira não pode ser mantida mesmo na teoria, os grupos de casos talvez não sejam expressivamente diferentes. A dificuldade que os tribunais têm encontrado em diferenciar entre produtos e serviços reflete que os casos envolvendo produtos não são de todo diferentes em primeiro lugar. Mesmo que casos envolvendo produtos têm significativos contrastes estéticos, não é fácil de os distinguir em políticas de base.

Isto não nega a possibilidade de coerentemente distinguir danos causados por produtos do restante dos danos pessoais. De fato, minha tese é no sentido de que problemas singulares de prova podem contar para o tratamento especial de casos de produtos e deveriam ser utilizados para definir a fronteira entre produtos e serviços. Mas essa razão é por ela mesma discutível: não é por si só evidente que os problemas de prova em casos envolvendo produtos são tão significativos que eles não possam ser atenuados por ônus de prova variáveis, dentro do sistema de culpa.

\section{Conclusão}

Sem serem consideradas as implicações mais amplas das dificuldades encontradas pelos tribunais em diferenciarem produtos de serviços, o problema específico de resolver casos híbridos de venda de produtos e serviços requer atenção. Os tribunais tatearam por soluções ad hoc em circunstâncias específicas, mas eles não desenvolveram uma aproximação compreensiva. Uma causa desta dificuldade foi o fracasso dos tribunais em desenredar a questão do produto-serviço das outras questões tipicamente apresentadas por casos envolvendo serviços. Uma segunda causa da dificuldade é o fato de os tribunais terem tentado distinguir produtos de serviços sem confiarem nas razões para tratarem de maneira especial danos causados por produtos.

A melhor explicação ao uso seletivo da responsabilidade objetiva em casos envolvendo produtos (strict procucts liability) é que os autores enfrentam problemas graves tentando provar atos remotos de culpa. Mesmo que esta razão seja rejeitada, entretanto, um tribunal deveria resolver casos híbridos de venda de produtos e serviços de acordo com seu próprio entendimento da razão para tratar caso envolvendo produtos distintamente. Esta aproximação não apenas produzirá uma melhor resolução dos casos 
híbridos envolvendo venda de produtos e serviços, mas também irá nos fornecer um melhor entendimento da natureza da responsabilidade objetiva por produtos (strict procucts liability). 